\title{
XI \\ FÓRUM DE LUTA PELA MORADIA DE NITERÓI: UMA EXPERIÊNCIA EXTENSIONISTA EM EDUCAÇÃO POPULAR EM TEMPOS DE PANDEMIA*
}

\author{
Ana Cristina Oliveira de Oliveira ${ }^{1}$ \\ Regina Bienenstein ${ }^{2}$
}

\begin{abstract}
Em 1948, quando começaram a demolir as casas térreas para construir os edifícios, nós, os pobres que residiamos nas habitacõos coletivas, fomos despejados e ficamos residindo debaixo das pontes. É por isso que eu denomino que a favela é o quarto de despejo de uma cidade. Nós, os pobres, somos os trastes velhos.
\end{abstract}

Carolina Maria de Jesus 1960,

Este capítulo discute o período recente da experiência extensionista multidisciplinar do Núcleo de Estudos e Projetos Habitacionais e Urbanos $(\mathrm{NEPHU})^{3}$ da Universidade Federal Fluminense (UFF), voltada para assessoria técnica e social de coletivos populares que integram o Fórum de Luta pela Moradia de Niterói e materializada no programa de extensão "A Universidade pú-

*DOI - 10.29388/978-65-86678-35-2-0-f.239-266

${ }^{1}$ Assistente Social. Doutora em Serviço Social. Professora Adjunta do Departamento de Serviço Social e do Programa de Pós Graduação em Serviço Social e Desenvolvimento Regional (mestrado) da Escola de Serviço Social da Universidade Federal Fluminense. e-mail: anacoliveira60@gmail.com.

2 Arquiteta e Urbanista. Doutora em Arquitetura e Urbanismo. Professora Titular do Programa de Pós-Graduação em Arquitetura e Urbanismo da Escola de Arquitetura e Urbanismo da Universidade Federal Fluminense. E-mail: bienenstein-regina@id.uff.br.

3 O NEPHU é um núcleo de apoio à extensão e à pesquisa, ligado à Pró-Reitoria de Extensão da Universidade Federal Fluminense (UFF), cuja experiência em assessoria técnica, iniciada em 1983, se realiza atualmente ao Fórum de Luta pela Moradia de Niterói e São Gonçalo e ao Conselho Popular da cidade do Rio de Janeiro, por uma equipe de docentes e discentes dos cursos de Serviço Social, Arquitetura e Urbanismo, Direito, Engenharia e Geografia que disponibilizam seus conhecimentos com a produção de planos populares, projetos arquitetônicos, elaboração de diagnósticos socioeconômicos, urbanísticos e ambientais, além de formação política, educação e mobilização popular. 
blica e o direito à cidade: assessoria aos movimentos sociais no Estado do Rio de Janeiro". Pretende-se discutir os desafios presentes e as perspectivas no desenvolvimento dessa ação, considerando as novas demandas a partir do enfrentamento da realidade de pandemia.

Está organizado em três partes além desta breve apresentação e das considerações finais. A primeira contextualiza o cenário no qual a experiência se desenvolve; a segunda apresenta a experiência extensionista e a terceira apresenta dificuldades e obstáculos enfrentados.

\section{O CONTEXTO EM TEMPOS DA PANDEMIA COVID 19}

A crise sanitária ${ }^{4}$ que assola o mundo desde o último outono de 2020, acompanha a própria formação da sociedade moderna. As pandemias, ao longo da história, atravessaram diversos espaços urbanos e rurais, dizimando parcela da população. Com a Covid-19, não está sendo diferente. Mundo afora, os impactos do COVID-19 (SARS-CoV-2) agudizaram e aprofundaram a crise econômica e política internacional, afetando de forma mais direta a classe trabalhadora na reprodução social, na produção de informações e na atuação dos governantes. Historicamente, "[...] as doenças que assolaram a humanidade nas mais diversas regiões do mundo tiveram repercussões e resultados que, de uma forma ou de outra, trouxeram mudanças significativas na reprodução social" (LARA, 2020, p. 55).

Os desdobramentos atuais do COVID-19 e suas repercussões na saúde, na economia, na política, no meio ambiente e na sociedade já são notórios quando se constata que, no Brasil, o número de mortos ultrapassa 130.000 mortos $^{5}$. A situação é agravada no campo do trabalho pela perda recente e pro-

4 Em janeiro de 2020, a Organização A Organização Mundial da Saúde (OMS) afirmou que o surto da doença causada pelo novo corona vírus (COVID-19) constitui uma Emergência de Saúde Pública de Importância Internacional, de acordo com o Regulamento Sanitário Internacional. Em 11 de março de 2020, a COVID-19 foi caracterizada pela OMS como uma pandemia. Disponível em:

< https://www.paho.org/bra/? gclid=EAIaIQobChMIqNarmoLY6wIVQQ6RCh0E5QExEAAYASAAEgIklPD BwE >.

Acesso em 07 set. 2020.

${ }^{5}$ Para maiores informações ver o painel corona vírus em: < https://covid.saude.gov.br $>$. Acesso em: 10 set. 2020. 
gressiva de direitos, a partir da flexibilização e precarização do trabalho, e com as novas condições de trabalho remoto com contratos de trabalho intermitentes ${ }^{6}$, cuja forma não garante qualquer benefício em caso de adoecimento pelo Coronavírus.

Dentre outros elementos, destacamos o alerta recente da Organização Pan-Americana da Saúde (OPAS) que conclui que a pandemia da COVID-19 pode aumentar os fatores de risco de suicídio, por afetar a saúde mental, gerando angústia, ansiedade e depressão, especialmente entre os profissionais de saúde e a parcela da população superexplorada ${ }^{7}$. Soma-se a isto, as questões de violência, transtornos por consumo de álcool, abuso de substâncias e sentimento de perda, incitando um acentuado aumento do risco de uma pessoa decidir tirar a própria vida ${ }^{8}$.

A COVID-19 escancarou e, sem dúvida, vem agravando a desigualdade social, com as condições exponencialmente mais precarizadas nas favelas do capitalismo dependente, com territórios não alcançados pelo saneamento (abastecimento d'água e esgoto sanitário domiciliar), onde se torna impossível garantir o mínimo de isolamento domiciliar com famílias inteiras restritas a um mesmo espaço, onde a iluminação e ventilação naturais são deficientes. Esta é a face da cidade brasileira, cotidianamente autoconstruída por seus moradores?

${ }^{6} \mathrm{O}$ trabalho intermitente foi fruto da (contra) Reforma Trabalhista do Temer (lei 13.467/2017) altera a Consolidação das Leis do Trabalho (CLT), aprovada pelo Decreto-Lei no 5.452, de 1o de maio de 1943, e as Leis nos 6.019, de 3 de janeiro de 1974, 8.036, de 11 de maio de 1990, e 8.212, de 24 de julho de 1991, a fim de adequar a legislação às novas relações de trabalho. Diário Oficial da União 14 jul/2017. A legislação dá a possibilidade de terceirização em todas as atividades gerando a queda do nível salarial, jornadas de trabalho mais longas, menor estabilidade e menos direitos

Para maiores informações ver: Brasil. Lei 13.467, de 13 de julho de 2017. Disponível em: < http://www.planalto.gov.br/ccivil 03/ ato2015-2018/2017/lei/113467.htm >. Acesso em: 28 ago. 2020.

A categoria superexploração da força de trabalho tratada por Ruy Mauro Marini como fundamento da teoria marxista da dependência (TMD) revela o caráter sui generis do capitalismo dependente, a superexploração da força de trabalho. A superexploração da força de trabalho, além de ter a intensificação e a ampliação da jornada de trabalho, também é explicitada pela remuneração abaixo do seu valor. Para maiores esclarecimentos sobre a categoria superexploração ver Marini (2005), Luce (2018) e Osorio (2009).

${ }^{8}$ Para maiores informações ver: < https://www.paho.org/bra/index.php? option $=$ com content $\&$ view $=$ article $\&$ id $=6277$ : pandemia - de - covid -19 -aumenta - fatores - de risco-para-suicidio\&Itemid=839Opas $>$. Acesso em: 10 set. 2020. 
As recomendações do protocolo de COVID-19 ${ }^{10}$, propostas para estes espaços são as mesmas recomendadas para a face da cidade dos privilégios, plena de serviços e infraestrutura. Ou seja, a proposta é da aplicação das mesmas orientações de proteção da Covid-19 nas diferentes realidades brasileiras ${ }^{11}$, sem considerar sua completa inviabilidade na cidade popular. Como fazer isolamento, se é necessário buscar a sobrevivência quando temos mais de três pessoas por cômodo nas moradias? Como lavar as mãos com frequência e manter limpo seu ambiente, quando não se tem acesso ao abastecimento de água e o esgoto corre a céu aberto?

Além desse cenário, há dificuldade de acesso a unidades de saúde e de assistência social; redução das doações, falta de testes, além dos obstáculos a serem ultrapassados para receber o auxílio emergencial do governo federal cujo valor sequer atinge o patamar do salário mínimo e que agora será reduzido ainda mais. São exigências burocráticas a cumprir, filas e aglomerações a enfrentar que colocam essa parcela da população em situação de extremo risco social. Mas os problemas enfrentados por essas pessoas não param aí. Somam-se a eles, as ameaças de remoção e despejo, parte delas resultado de ações públicas, parte decorrentes de processos de reintegração de posse consumados, apesar da decisão do Supremo Tribunal Federal (STF) proibindo que isso aconteça durante a pandemia.

Importante considerar que os impactos da pandemia e pós-pandemia sobre a população mais explorada, a adoção de estratégias do tipo contratos intermitentes que chegam a criar 20,5 mil vagas, enfim o desmonte do conjunto

\footnotetext{
${ }^{9}$ Ver BIENENSTEIN, G.; BIENENSTEIN, R.; SOUSA, D. M. M. O Coronavírus, a Cidade e a Arquitetura: o caso brasileiro como um (possível) laboratório de horrores. In: BORGES, A.; MARQUES, L. (Orgs). Coronavírus e as Cidades Brasileiras: reflexões durante a pandemia. Rio de Janeiro: Outras Letras, 2020. p. 96-100.

${ }^{10}$ Para maiores informações ver: < https://coronavirus.saude.gov.br/>. Acesso em: 11 set. 20.

11 Os moradores/as de favela e periferia, os povos originários da terra, os ribeirinhos, as pessoas em situação de rua, os refugiados, o povo cigano, aqueles que (con)vivem com alguma deficiência física ou mental/doença crônica, pessoas em privação de liberdade, as LGBTQI+, os/as catadores/as e trabalhadores/as da reciclagem, trabalhadores/as remotos de aplicativos, trabalhadores/as intermitentes, ou seja, pessoas que estão de alguma maneira expostos, e outros grupos da superpopulação relativa (MARX, 2013) têm algo em comum: lidar com as desigualdades no acesso aos direitos, o que os torna ainda mais precarizados diante da pandemia de Covid-19. Para maiores informações ver: $<$ https://portal.fiocruz.br/noticia/desigualdadesocial-e-economica-em-tempos-de-covid-19>. Acesso em: 01 set. 2020.
} 
de direitos, arduamente conquistados ao longo de décadas, poderá conduzir ao aumento exponencial do desemprego e à precarização ainda maior de suas condições de vida, já que isto ocorre em um país onde uma parte da população sobrevive com menos de um salário mínimo e milhões estão desempregados/as ou subempregados/as. Ainda não podemos dimensionar os impactos, tanto na vida, quanto na organização da sociedade, mas podemos identificar o agravamento da crise do capital ${ }^{12}$ e da desigualdade social, situação anterior à pandemia que já se apresentava avassaladora na reprodução das relações sociais, em especial para a população das favelas e periféricas. (CHESNAIS, 2020).

A esse respeito, Antunes $(2019 ; 2020)^{13}$ nos alerta para um outro aspecto dessa situação que também é agravada pelas novas formas de trabalho remoto da era digital "do ponto de vista de seu impacto nas relações de trabalho, a flexibilização se expressa na diminuição drástica das fronteiras entre atividade laboral e espaço da vida privada, no desmonte da legislação trabalhista, nas diferentes formas de contratação da força de trabalho e em sua expressão negada, o desemprego estrutural".

Por outro lado, é importante considerar que os trabalhadores/as dos espaços populares se veem forçados a sair, seja para o trabalho informal, com atividades nas ruas, seja para o trabalho formal, por vezes enfrentando ambientes insalubres, mas sempre com deslocamento em transportes coletivos lotados. Apesar de apresentarem ainda, um alto índice de contaminação e mortes, progressivamente, as cidades retornam para o que chamam de "novo normal", utilizando justificativas econômicas e apontando ser possível se resguardar na rua. O que fica claro é que o isolamento social não é para todos e que o anunciado "novo normal" se refere às condições impostas ao trabalhador/a, obrigado a romper diariamente com o distanciamento social indicado por especialistas e pela Organização das Nações Unidas (ONU).

Buscamos até aqui recuperar, ainda que muito rapidamente, elementos do contexto e especialmente da situação enfrentada cotidianamente pela população protagonista da experiência de extensão universitária, foco desta reflexão.

${ }^{12}$ Chesnais (2020) analisa a crise mundial que vivemos hoje e a pandemia do Covid 19 como consequência social, econômica, do aquecimento global e das tecnologias dominantes. Para maiores informações ver: CHESNAIS, 2020.

${ }^{13} \mathrm{O}$ autor analisa o futuro do trabalho no Brasil e a nova massa superexplorada da era dos serviços digitais. Ver: ANTUNES (2019; 2020). 
O item a seguir resume os principais componentes da ação do NEPHU, completando assim, o cenário onde se desenvolve a ação extensionista aqui examinada.

\section{BREVE REVISÃO DA EXPERIÊNCIA DA EXTENSÃO UNIVER- SITÁRIA CONTRA HEGEMÔNICA EM DIREITO À CIDADE E EDUCAÇÃO POPULAR NA REGULARIZAÇÃO FUNDIÁRIA}

A experiência de extensão universitária que o NEPHU desenvolve, nos últimos 35 anos, vem construindo ações que permitem a socialização de conhecimento sobre o território (leia-se espaços populares) e a participação popular. A experiência na extensão com este pressuposto incrementa a assistência técnica, social e jurídica, de forma interdisciplinar, a moradores de inúmeros assentamentos populares que lutam pelo direito à moradia e à cidade, situados no estado do Rio de Janeiro, destacando-se os municípios de Niterói, São Gonçalo e Rio de Janeiro.

O Programa "A Universidade pública e o direito à cidade: assessoria aos movimentos sociais no Estado do Rio de Janeiro" do NEPHU, iniciado em 2017, objetiva subsidiar movimentos sociais dos municípios de Niterói, São Gonçalo, Rio de Janeiro, Seropédica e Volta Redonda que lutam pelo direito à cidade, entendido não apenas com o direito aos serviços públicos e à moradia, mas também o direito a um planejamento urbano que esteja voltado para a ampliação das condições de acesso aos benefícios da vida urbana. As áreas onde atuar e os temas a serem desenvolvidos no Programa e em seus projetos foram definidos coletivamente em fóruns de cada cidade que agregam movimentos sociais e grupos comunitários, e poderão ser por eles adaptados e complementados. O programa é formado por cinco projetos que se articulam e compreendem ações de ensino, pesquisa e extensão. São eles: (1) Formação Política, Educação Popular, Direitos Sociais e Serviço Social; (2) Assessoria jurídica a movimentos sociais para a efetivação do direito à cidade e do direito à moradia; (3) A Universidade e o direito à cidade: acompanhando e mapeando os conflitos; (4) Curso de Extensão em direito à cidade: planejamento conflitual ${ }^{14}$ e participa-

14 Para o conceito de planejamento conflitual ver OLIVEIRA, F. L. de; SÁNCHEZ, F.; VAINER, C. (2020). 
tivo; e (5) Projeto Popular de Regularização Urbanística e Fundiária Plena da Fazendinha-Sapê. A definição dos temas específicos desenvolvidos no curso de extensão e respectivos professores fizeram parte do escopo do projeto, sendo realizada pelos coletivos comunitários e professores que participam do progra$\mathrm{ma}^{15}$.

Para o desenvolvimento deste trabalho é adotada metodologia que, por meio de um processo dialogal, incorpora a população em processos decisórios vinculados a todas as suas etapas. Nesse sentido, parte-se do pressuposto de que a população deve ser protagonista nas decisões relativas ao seu espaço de morar, reconhecendo-a como um planejador popular e como um importante elemento na definição coletiva de propostas e encaminhamentos, permitindo assim a definição coletiva e negociada de todas as propostas e encaminhamentos. Trata-se de possibilitar ao cidadão dos espaços populares o direito de interferir em seu espaço de morar, de ter acesso a um projeto arquitetônico e urbanístico, ao saber técnico e à participação na concepção dos planos e projetos.

Vale destacar que a atuação do NEPHU tem compreendido projetos de extensão, articulados a pesquisas, dentro dos seguintes eixos temáticos: assessoria técnica e social em projetos de habitação, urbanismo e regularização fundiária plena ${ }^{16}$; planejamento em situação de conflito; formação política do direito à cidade; impactos de grandes projetos regionais na informalidade habitacional e transmissão de conhecimento à população e aos gestores locais.

Durante o ano de 2017, o NEPHU foi procurado por algumas comunidades de Niterói que começavam um movimento no sentido de conseguir melhorar suas condições de moradia e ter acesso não só aos ônus da vida urbana, mas também às vantagens que ela poderia oferecer. Foi formado, assim, o Fórum de Luta pela Moradia de Niterói e São Gonçalo que reúne Associações de Moradores, movimentos sociais, moradores/as, lideranças da luta por moradia digna e diferentes grupos comunitários dos dois municípios, onde a equipe do

\footnotetext{
15 As ações podem ser vistas na página do Programa: < http://nephu.sites.uff.br/programa/ > Acesso em: 04 set. 2020. . (BIENENSTEIN, 2020).

${ }^{16}$ Entende-se Regularização Fundiária Plena como processo voltado para garantir a segurança da posse da terra, agregando qualidade à moradia enquanto direito. Trata-se de processo que inclui as dimensões jurídica da propriedade da terra e também a social, a urbanística e a ambiental. Isto significa que situações variadas de risco e de violações de direitos a que a população possa estar submetida serão analisadas e trabalhadas (BIENENSTEIN, 2001).
} 
NEPHU já vinha atuando e, passaram a participar nas discussões das questões relativas ao direito à cidade. Em paralelo a isso, no Rio de Janeiro, a partir de 2011, após apoiar a resistência de comunidades como a Vila Autódromo, Arroio Pavuna e Vila União Curicica contra a remoção ${ }^{17}$, em articulação com o Núcleo de Terras da Defensoria Pública do Estado do Rio de Janeiro e o Laboratório Estado, Trabalho, Território e Natureza (ETTERN/IPPUR/UFRJ), a equipe do NEPHU seguiu acompanhando essas comunidades na busca por melhorias em seus territórios, participando do Conselho Popular-Rio.

Nesta direção, um dos objetivos das ações extensionistas do NEPHU é contribuir para o processo de fortalecimento de grupos sociais que atuam na perspectiva do direito à cidade, mediante a participação no Fórum de Luta por Moradia, através de um trabalho de acompanhamento das ações realizadas no mesmo. A direção social, técnica e política das ações é possibilitar, a partir das demandas apresentadas pelos integrantes do Fórum, a realização de ações que fortaleçam o processo de mobilização e a garantia de direitos dos trabalhadores. Além disso, aprofundar o debate sobre a questão urbana, direitos sociais e as formas de resistência e organização dos trabalhadores pela educação popular, ratificando, em especial, o papel da Universidade Pública socialmente referenciada, em relação às demandas reais da classe trabalhadora e às expressões da questão social.

As ações extensionistas são demandadas pelos movimentos sociais e comunidades que participam do Fórum de Luta por Moradia com as seguintes abordagens: aprofundando o debate sobre a questão urbana e direitos sociais e as formas de resistência e organização dos/das trabalhadores/as; formação política com grupos sociais, movimentos sociais e familiares do Fórum de Luta por Moradia; oficinas temáticas e demandas no Fórum, entre eles, educação, regularização fundiária, saneamento básico, remoção, deslizamento, direitos pre-

17 Cabe destacar ainda que, anterior a este contexto da aprovação da Lei Federal n ${ }^{\circ} 13.465$ de 2017, que versa sobre a regularização fundiária urbana e rural, já havia surgido mobilizações contra os megaeventos, o aumento da tarifa dos transportes públicos e também contra as remoções forçadas de comunidades localizadas nas fronteiras urbanas valorizadas pelo capital imobiliário, indicando uma possível ampliação da luta por melhores condições de vida e uma tendência que o antropólogo James Holston (2016, p. 191-195) denomina cidadania insurgente. Para o autor, tais movimentos seriam capazes de criar uma pauta de exigências voltada para os espaços da cidade, que podiam não coincidir com as prioridades colocadas pelo Estado. 
videnciários, direitos da criança e adolescente, direitos da família e direitos trabalhistas, direitos e benefícios sociais, enfrentamento ao COVID-19 e favela; e ratificação do papel social da Universidade Pública vinculado às demandas reais da classe trabalhadora e as expressões da questão social.

Desde o início da experiência em 1983 e sua institucionalização em 1986, como NEPHU, o trabalho parte da perspectiva da indissociabilidade do tripé: ensino, pesquisa e extensão. A título de ilustração pontuamos que os estudos e as ações de pesquisa e extensão têm percorrido a constituição urbana fluminense, o desenvolvimento capitalista desigual e combinado que impulsiona a conformação de diferentes territórios na cidade, as diferentes dimensões da vida cotidiana, o processo de mercantilização da cidade, e a organização dos movimentos sociais urbanos.

As ações extensionistas, ao articular professores, alunos de graduação e pós-graduação, pesquisadores das áreas diversas do conhecimento ${ }^{18}$, integra a população que luta pelo direito à cidade e à moradia digna, através da realização de ações diversas com os movimentos sociais urbanos e moradores que integram o Fórum de Luta por moradia, além de produção técnica por eles demandada, necessária ao processo de melhoria das condições habitacionais, sociais e ambientais.

A proposta na mesma linha do saber-aprendizagem e formação política e participação popular volta-se para capacitação de estudantes graduandos, recém-formados, pós-graduandos, lideranças comunitárias e de movimentos sociais urbanos, e moradores das áreas atendidas. Representa um espaço do qual participam professores e estudantes de mestrado e doutorado das diferentes áreas, ministrando aulas e desenvolvendo oficinas, a partir do detalhamento dos temas específicos que são definidos pela comunidade em conjunto com professores e estudantes.

\footnotetext{
${ }^{18}$ A participação das diferentes áreas no Programa se dá pelos seguintes departamentos de ensino e programas de pós-graduação e núcleos e grupos de pesquisa e extensão da UFF: Departamento de Direito Público (SDB) e Programa de Pós-graduação em Direito Constitucional (PPGDC); Departamento de Serviço Social, Núcleo de Estudos e Pesquisas sobre Favelas e Espaços Populares (NEPFE) e Núcleo de Estudos e Pesquisas sobre Teoria Social, Trabalho e Serviço Social (NUTSS); Departamento de Urbanismo e Programa de Pós-graduação em Arquitetura de Urbanismo (PPGAU); o Departamento de Engenharia Civil e grupo de Recursos Hídricos e o grupo de pesquisa Grandes Projetos de Desenvolvimento Urbano, vinculado ao Programa de Pós-Graduação em Arquitetura e Urbanismo (GPDU/PPGAU).
} 
O Programa, portanto, inclui algumas frentes de atuação que se articulam principalmente na defesa dos territórios populares (espaços populares), abrindo um importante ambiente de participação e contribuição para uma Universidade púbica, gratuita, laica, de qualidade e socialmente referenciada.

Neste sentido, a atuação da Universidade, por ainda ser dotada de autonomia, pode desempenhar uma assessoria técnica e social às populações dos espaços populares e das favelas que permita desvelar processos opressivos, dar voz a essa parcela da população que tende a ser invisibilizada, além de experimentar caminhos inovadores e apontar diretrizes para a implantação de ações voltadas para o direito à cidade, enquanto política pública.

\section{EXTENSÃO UNIVERSITÁRIA E EDUCAÇÃO POPULAR: OBS- TÁCULOS E DESAFIOS NA PANDEMIA}

O NEPHU desenvolve a assessoria técnica interdisciplinar, no enfrentamento da desigualdade social e da superexploração do trabalho aos grupos sociais e movimentos sociais de forma orgânica, quais sejam, de forma permanente e articulada e no lastro da formação política. Isto significa que se trata de construir ações de formação continuada que estejam engajadas na luta pelo direito à cidade mediante a metodologia da educação popular.

Nesta direção, a assessoria técnica interdisciplinar desenvolvida junto ao Fórum está circunscrita como uma expressão da extensão universitária ao movimento social urbano na luta pelo direito à cidade junto às organizações da classe trabalhadora, cuja incursão se dá no capitalismo dependente pelo padrão de dominação externa (FERNANDES, 2009) marcada pela desigualdade social e expropriação permanente de suas riquezas (OLIVEIRA; SANTOS; BIENENSTEIN, 2019, p. 53, grifos dos autores).

Entendemos que uma universidade pública, gratuita, laica, com elevado padrão de qualidade e socialmente referenciada tem como elemento essencial a indissociabilidade das atividades de ensino, pesquisa e extensão. Com este pressuposto, as suas ações fortalecem para coadunar com a produção de conhecimentos, na formação de profissionais e na prestação de serviços à comunidade 
alicerçada no seu compromisso social. Portanto, como afirma Goergen (1999, p. 20),

A universidade precisa, em todas as suas áreas, recuperar sua capacidade reflexiva sobre os grandes eixos da cultura atual, seja do ponto de vista científico/tecnológico, seja do ponto de vista humanístico/cultural. A universidade precisa quebrar o grilhão do individualismo, do isolamento, do corporativismo e do egoísmo e gerar uma solidariedade fecunda como sementeira de uma nova forma de ser, de agir e de saber.

Atualmente, a construção metodológica das ações extensionistas se desenvolve nas reuniões do Fórum de Luta por Moradia, em assembleias comunitárias e oficinas temáticas, entre outras ações. Além disso, são elaborados em conjunto e par e passo com os moradores, projetos urbanísticos voltados para a melhoria da qualidade da moradia e do meio ambiente, e eliminação de situações variadas de risco. Estes representam espaços adicionais de formação e diálogo com os moradores dos territórios populares. Todas as intervenções são atravessadas pela cultura popular e cidadania, objetivando a criação de espaços de formação de sujeitos construtores ativos da sociedade.

Nesta direção, a perspectiva metodológica pautada na ontologia do ser social e na teoria social crítica intenciona, portanto, compartilhar saberes, aprendizados, experiências, caminhos, vislumbrando a troca de experiência e ampliando as possibilidades de cooperação entre educadores e pesquisadores que trabalham na extensão universitária.

A experiência vivenciada nas ações extensionistas está marcada, assim, por um movimento dialético e tem como base a educação popular que se refere ao uso da dialética / dialogicidade na relação educador e educando. Com este enfoque a relação educador - educando é (re)criada numa perspectiva horizontal. Esta experiência, enquanto prática democrática e participativa, se conforma diante de uma abertura do educador que não se coloca como o único detentor de conhecimento, conforme salienta Paulo Freire (1998, p. 127):

Se, na verdade, o sonho que nos anima é democrático e solidário, não é falando aos outros, de cima para baixo, sobretudo, como se fôssemos os portadores da verdade a ser transmitida aos demais, que aprendemos a escutar, mas é escutando que apreendemos a falar com eles. 
Possibilita, assim, condições para uma maior interação entre participantes da comunidade atendida e a universidade. Nessa perspectiva, o trabalho de extensão possibilita uma melhor relação entre o conhecimento do educador e a realidade circundante pelo conhecimento dos grupos sociais que participam do Fórum de Luta por Moradia, além de promover "[...] maior interesse dos destinatários que não seriam mais vistos como meros receptores e sim, atores dentro de um processo". (THIOLLENT, 2000, p. 23). Na verdade, "ninguém educa ninguém, ninguém educa a si mesmo, os homens se educam entre si, mediatizados pelo mundo" (FREIRE, 1997, p. 68). Portanto, assevera Thiollent (2000, p. 23):

Com a metodologia participativa, um projeto de extensão traz uma melhor relação entre o conhecimento do pesquisador e a realidade circundante, maior interesse dos destinatários que não seriam mais vistos como meros receptores e sim, atores dentro de um processo. Além disso, torna-se possível detectar novas questões específicas, para as quais seriam necessários estudos ou pesquisas mais aprofundadas, inclusive de modo associado à realização de teses de pós-graduação.

Nesse momento de crise mundial do capital, ampliada pela crise sanitária, a expressão da desigualdade social na extensão universitária tem como horizonte gerar alternativas para a continuidade da vida em sociedade. A extensão universitária é entendida como o momento de elo com a pesquisa e o ensino, num processo de ensino-aprendizagem, na construção da formação política e humana, tendo o popular como central na produção do conhecimento. É na extensão universitária que se pode reforçar o popular no fazer-acadêmico, na medida em que é no popular trazido através da extensão universitária, que se cria um novo mecanismo do tripé ensino, pesquisa e extensão.

A extensão universitária permite que ocorra a aproximação, a integração e a parceria entre os projetos institucionais e a comunidade. Hoje, esse fluxo, interrompido e suspenso pela pandemia COVID 19, apresenta desafios relativos à impossibilidade do encontro presencial, aos limites de acesso tecnológico e de forma também evidente para professores e estudantes que desenvolvem a extensão, a sua secundarização frente ao ensino e à pesquisa. As ações 
extensionistas, sejam de interesse geral, sejam aquelas vinculadas aos movimentos sociais, sentem o reflexo de serem colocadas em segundo plano, enfatizando-se as ações de assistência técnica mercadorizável.

Por conseguinte, parte significativa das ações de extensão desenvolvidas atualmente nas universidades públicas está reduzida a cursos pagos, prestação de serviços assistenciais, escritórios modelos, empresas Junior, entre outras formas, de modo que tais práticas estão sintonizadas ao processo de privatização por dentro das universidades brasileiras. Entende-se que há uma lógica de compra e venda de serviços que deturpa a concepção de extensão universitária. Considera-se que aquela que privilegia e dialoga de forma crítica e comprometida com a comunidade reafirma a concepção de uma universidade pública, gratuita, laica, de qualidade e socialmente referenciada (OLIVEIRA; SANTOS; BIENENSTEIN, 2019, p. 54, grifo dos autores).

O distanciamento social nos impôs revermos os processos educativos e buscarmos alternativas para garantir as ações extensionistas, diante dos riscos iminentes de contágio e morte. Em que condições a assessoria técnica e social de coletivos populares que integram o Fórum de Luta pela Moradia de Niterói materializa o programa de extensão "A Universidade pública e o direito à cidade: assessoria aos movimentos sociais no Estado do Rio de Janeiro"?

Em texto produzido pelo coletivo de coordenadores do NEPHU, ainda antes da pandemia, sinalizamos como compreendemos a extensão universitária:

Tratar da extensão universitária junto aos movimentos sociais urbanos significa construir um espaço de resistência dentro da universidade pública. Apesar dos ataques que tem sofrido no atual governo, essa universidade ainda pode ser considerada um lócus fundamental de produção de conhecimento sobre as distintas formas construídas pela classe trabalhadora para sobreviver (OLIVEIRA; SANTOS; BIENENSTEIN, 2019, p. 53 , grifos dos autores).

$\mathrm{Na}$ realidade pandêmica do trabalho remoto, precarizado e temporário, como transitar pela vivência de uma extensão que consiga manter o compromisso com as classes populares, num cenário de escassez de recursos financei- 
ros institucionais para a extensão, com a precarização de acesso às redes sociais e internet que se constituem somente de forma privada?

A experiência da extensão universitária desenvolvida pelo NEPHU, discutida neste texto, vem reafirmando a função social da universidade com a realização de ações contra hegemônicas na articulação entre a universidade pública e os movimentos sociais urbanos, entendendo-a como uma estratégia de resistência e luta perante as desigualdades sociais. Aqui se estabelece uma relação da educação (não-formal) com os movimentos sociais, entendendo que nesta relação há aprendizagem e produção de saber, gerados em outros espaços para além da educação escolar (formal), num sentido mais amplo de educação. Se assim o é, o caráter educativo presente nas práticas que se situam no ato de participar pressupõe negociações, diálogos ou confrontos, portanto, no entender outros espaços educativos em movimentos e ações coletivas, como geradores de aprendizagens e saberes.

Uma das premissas básicas a respeito dos movimentos sociais é: são fontes de inovação e matrizes geradoras de saberes. Entretanto, não se trata de um processo isolado, mas de caráter político-social. Por isso, para analisar esses saberes, deve-se buscar as redes de articulações que os movimentos estabelecem na prática cotidiana e indagar sobre a conjuntura política, econômica e sociocultural do país quando as articulações acontecem. Essas redes são essenciais para compreender os fatores que geram as aprendizagens e os valores da cultura política que vão sendo construídos no processo interativo (GOHN, 2011, p. 333-334).

A perspectiva contra hegemônica desenvolvida junto aos movimentos sociais se pauta na formação política continuada de modo que possa contribuir no processo de qualificação de dirigentes, militantes e famílias engajadas na luta pelo direito à cidade e à moradia, mediante a metodologia da educação popular. Nesse sentido, e para auxiliar este debate, inicialmente apresentamos a perspectiva de formação política e posteriormente a de educação popular.

A formação, vinculada ao desenvolvimento da construção de um pensamento coletivo em seus aspectos objetivos, está voltada para o preparo social e político-pedagógico de apreender e formular planos de mudanças da realidade analisada. Isto significa construir um processo voltado para atores sociais coletivos, que contribua na produção de conhecimentos e ações que possam inter- 
ferir na lógica de política dos distintos sujeitos. Por isso, lançar mão da educação popular difere de ações restritas a treinamento ou da simples transmissão de informações. Significa, assim, a criação de um senso crítico que leve as pessoas a entender, comprometer-se, elaborar propostas, cobrar e transformar(se).

Trata-se de um processo coletivo de produção e socialização do conhecimento que permita educadores e educandos a ler criticamente a realidade sócio-econômico-político-cultural, com a finalidade de transformá-la. Tornase um instrumento que desperta, qualifica e reforça o potencial popular de construir uma alternativa solidária.

A educação popular por nós entendida é uma educação de classe. Uma educação comprometida com os segmentos populares da sociedade, cujo objetivo maior deve ser o de contribuir para a elevação da sua consciência crítica, do reconhecimento da sua condição de classe e das potencialidades transformadoras inerentes a essa condição (VALE, 1992, p. 57).

Assim, coadunado com as ideias de Bogo (2000), podemos afirmar que a consciência está impregnada de conteúdo ideológico que se manifesta através de objetos materiais que adquirem um significado representativo que se localiza "fora" do indivíduo. Porém, não são as mudanças na consciência que transformam a realidade, nem as transformações na realidade mudam por si só o jeito de pensar e conceber o mundo. Necessário é a relação dialética entre o Ser e o Pensar. O determinante nesta relação são as condições materiais que influem na consciência dos indivíduos. É nesta relação que se dá o processo de formação da consciência, onde se torna possível interpretar os fenômenos do real que estão além da aparência e assim, perceber a realidade como um todo complexo que está sendo, algo dinâmico, em movimento e marcado por sua historicidade.

Conforme aponta Mauro Iasi (2007, p. 13),

O processo de consciência é visto, de forma preliminar e introdutória, como um desenvolvimento dialético, onde cada momento traz em si os elementos de sua superação, onde as formas já incluem contradições que ao amadurecerem remetem a consciência para novas formas e contradições, de maneira que o movimento se expressa num processo que contém saltos e recuos. 
Neste sentido, torna-se relevante apontar uma perspectiva de formação que não seja focal ou imediatamente voltada para suprir necessidades pontuais sobre determinado conhecimento, mas uma proposta que considere o ire-vir, os recuos e avanços, que é o processo de formação da consciência. Para isto, torna-se importante voltar a pensar do ponto de vista metodológico, qual seria a forma de construirmos ou utilizarmos uma determinada categoria que possa estabelecer vínculos com o objetivo da proposta.

A dimensão da educação popular, aqui entendida como “[...] uma gama ampla de atividades cujo objetivo é estimular a participação política de grupos sociais subalternos na transformação das condições opressivas de sua existência social" (SILVA, 2000, p. 24). Esse é um elemento fundamental para pesar a formação política dos sujeitos envolvidos na luta pelo direito a cidade.

É na contra mão de uma perspectiva de uma educação que legitime os interesses da classe dominante que se aposta na educação popular, ou seja, é preciso considerá-la como uma metodologia de educação libertadora. Mézáros (2005) reforça a educação como função de transformar o trabalhador/a em um agente político que pensa, age, e usa a palavra como arma para transformar a realidade. Assim, apostar na dimensão da educação popular significa considerar o saber produzido pelos indivíduos, onde estes apresentam conhecimentos diferenciados que expressam sua leitura da realidade de um determinado ponto de vista. Estes conhecimentos representam suas experiências, seus pontos de vista e a forma que os homens e as mulheres lidam objetivamente com sua vida social.

A educação, que poderia ser uma alavanca essencial para a mudança, tornou-se instrumento daqueles estigmas da sociedade capitalista: fornecer os conhecimentos e o pessoal necessário à maquinaria produtiva em expansão do sistema capitalista, mas também gerar e transmitir um quadro de valores que legitima os interesses dominantes. Em outras palavras, tornou-se uma peça do processo de acumulação de capital e de estabelecimento de um consenso que torna possível a reprodução do injusto sistema de classes (MÉZÁROS, 2005).

Por entender que a formação está diretamente vinculada aos processos de consciência e necessariamente com a dimensão ideológica estruturante da vida social, avaliamos que as contribuições de Antônio Gramsci podem deixar 
pistas para nossa reflexão. Gramsci detalha que a ideologia é tanto um elemento de dominação - uma vez que desde a entrada do homem no mundo consciente lhe é imposta uma concepção de mundo mecanicamente -, quanto pode ser um elemento de libertação, quando ocorre a elaboração de uma concepção de mundo própria dos grupos subalternos, na superação da influência da ideologia da classe dominante, o que é imprescindível para "[...] romper a unidade baseada na ideologia tradicional, sem cuja ruptura a força nova não poderia adquirir consciência da própria personalidade independente" (GRAMSCI, 1976, p. 11). Neste sentido, a dominação ideológica provoca, nas classes sociais subalternizadas, uma dicotomia entre o pensar e o agir, sendo possível dizer que o indivíduo possui:

[...] duas consciências teóricas (ou uma consciência contraditória) uma implícita na sua ação, e que realmente o une a todos os seus colaboradores na transformação prática da realidade e outra superficialmente explicita ou verbal, que ele herdou do passado e acolheu sem crítica. Toda via esta concepção verbal não é inconsequente: ela liga um grupo social determinado, influi sobre a conduta moral, sobre a direção de vontade, de uma maneira mais ou menos intensa que pode, inclusive, atingir um ponto na qual a contraditoriedade da consciência não permita nenhuma ação, nenhuma escolha, produza um estado de passividade moral e política (GRAMSCI, 1978, p. 20).

Quando Gramsci fala de consciência contraditória, está se remetendo à questão do senso comum, que seria justamente uma mistura desordenada de elementos da ideologia dominante - abstraídos da própria experiência de vida (GRAMSCI, 2001). Porém, admitia que o "senso comum" possuía um caroço de 'bom senso', a partir do qual poderia desenvolver o espírito crítico.

Assim, devemos ter nitidez que o descortiçamento da realidade, ofuscado pelo brilho da ideologia capitalista, é um processo lento, gradual e formado por etapas. Ou seja, o processo de formação da consciência ocorre numa intensa dinâmica prático-teórica capaz de dar sustentação ao trabalho e onde o estudo deve ganhar força e sentido, quando estiver colado com a prática política e organizativa dos grupos sociais. Neste ínterim, a proposta do projeto aqui abordado inclui a realização de oficinas de formação política para a coordenação e lideranças comunitárias, bem como oficinas temáticas que tratem de questões 
do cotidiano das famílias envolvidas com a luta por moradia, a fim de contribuir no processo de formação da consciência desses sujeitos e luta por acesso aos direitos historicamente conquistados pela classe trabalhadora.

Conforme destacado por Helfreich, o vazio entre a educação popular e a universidade é identificado pela escassez de projetos de extensão.

Outro elemento a destacar é o abismo entre a Educação Popular e a Universidade que se clarifica, sobretudo, na raridade de projetos de extensão que poderiam ser desenvolvidos envolvendo professores e alunos. A Extensão Universitária, entendida sob o princípio constitucional da indissociabilidade entre ensino, pesquisa e extensão, constitui-se como um processo interdisciplinar educativo, cultural, científico e político que deveria promover a interação transformadora entre universidade e outros setores da sociedade, mas que vem sendo subsumida ao ensino e, acima de tudo, aos experimentos de pesquisa que são muito mais valorizados pelas instituições de fomento e pelo próprio Ministério da Educação e Cultura (MEC). Poucas são as universidades que desenvolvem projetos de extensão no campo da educação popular e da formação política (SANTOS, 2017, p. 316-317),

O Programa, por oferecer um caráter permanente no envolvimento de ações com comunidades, não é interrompido, sendo continuado mesmo durante as férias da Universidade e agora, durante a pandemia da COVID-19. Esse diferencial na compreensão sobre assessoria técnica a movimentos sociais urbanos, grupos sociais, lideranças comunitárias e moradores dos espaços populares nos leva a crer que o desafio se coloca em cena de forma mais aguda. Vivemos a secundarização da extensão, com os alunos de graduação e pós-graduação, participando sem qualquer auxílio financeiro, o que implica numa atuação que depende da possibilidade, disposição e disponibilidade desses estudantes para que as ações sejam continuadas, mesmo de forma precarizada. Sem apoio financeiro, a viabilidade das ações tende a ficar mais limitada. Mesmo assim, o compromisso dos alunos não diminui sua capacidade de participar na produção acadêmica, eventos científicos, publicações e ações de difusão de conhecimento adquirido por meio dessas atividades, o que não reduz a importância e necessidade da efetiva valorização da extensão universitária.

Considerando as condições de estudo/trabalho desenvolvidas por meio das tecnologias de informação e comunicação, as ações têm indicado processos 
de intensificação e precarização dessas condições. O custo para o acesso ao uso da tecnologia, conexão de internet e utilização de dispositivos para dar continuidade às ações, que se concentram online, configuram elementos cruciais neste período pandêmico. Além do prejuízo na dedicação exclusiva ao Programa, tendo em vista a necessidade de busca por geração de renda para a sobrevida, indica, também, um prejuízo ou mesmo redução de algumas das ações.

Neste sentido o tratamento marginal à extensão universitária tem sido um dos desafios enfrentado pelo NEPHU, sendo agudizado na pandemia onde, apesar das publicações e premiações ${ }^{19}$, tem sido relegada à escassez de apoio financeiro, apesar da ampliação das ações neste período. Entretanto, para não interromper esta ação, seguindo o planejamento das atividades em caráter emergencial de ações extensionistas, os alunos/as continuaram ativos, até o presente momento. Consideram a realidade dos espaços populares radicalmente diferente dos demais territórios urbanos da cidade, por não contar de forma integral com os serviços fundamentais para o cuidado com a vida, e por ser o lócus espacial onde é inquestionável o impacto mais significativo da pandemia, a despeito da expressiva subnotificação nestas áreas da cidade.

A partir da pandemia, todas as ações que tem sido desenvolvidas online com a já mencionada precariedade do acesso à internet, neste período pandêmico, estão em consonância com as orientações das autoridades sanitárias e, com base na ciência nos diferentes níveis, organizam e articulam grupos de trabalho que analisam as condições e possibilidades em diversas frentes, a saber: (i) participação em eventos científicos sobre o tema direito à cidade; (ii) realização do vídeo institucional da UFF realizado no início da pandemia ${ }^{20}$; (iii) ações de solidariedade ativa, como parte de uma rede de luta e solidariedade denominada União de Fóruns de Luta de Niterói e São Gonçalo, composta por vários coletivos como Movimento dos Trabalhadores Sem Terra (MTST) e Movimento de Luta de Bairros, Vilas e Favelas (MLB), SINTUFF, ADUFF, Fórum de São

19 O NEPHU desde a criação tem sido reconhecido nacional e internacionalmente, tendo inclusive recebido o Prêmio Internacional "Urban Age Award" (concedido pelo Deutsche Bank para o Plano Popular da Vila Autódromo - 2013). Importante considerar que o Programa, no ano de 2018, mereceu o primeiro e o terceiro lugares e no ano de 2019, o segundo lugar na premiação da Semana de Extensão, XVI e XVII Prêmio Josué de Castro, respectivamente.

20 Para maiores informações ver o site institucional: < https://www.youtube.com/watch? $\underline{\mathrm{v}=\mathrm{oE} 2 \mathrm{UST} \text {-OuE\&feature }=\text { youtu.be }}>$. Acesso em: 05 ago. 2020. 
Gonçalo, Fórum de Saúde, SEPE, que se juntaram para arrecadar doações e viabilizar a distribuição de cestas básicas para os trabalhadores/as dos espaços populares, incluindo famílias integrantes do Fórum de Luta pela Moradia, configurando uma forma de resistência e luta pela permanência no território e pelo direito ao isolamento social; (iv) realização de reuniões quinzenais virtuais com oficina e assessoria prévia para o manejo da plataforma com moradores de comunidades, assentamentos populares e lideranças de áreas populares que integram o Fórum de Luta pela Moradia, com a crescente participação, o que indica a importância desse diálogo e reflexão coletiva sobre seus problemas; (v) pesquisa online sobre os reflexos da Covid-19 nessas áreas, atualizando assim o mapeamento sobre as condições de moradia e vida nesses territórios populares, onde a maioria são mulheres negras, favorecendo para desvendar os riscos iminentes de ocultação e invisibilização dos dados públicos sobre a contaminação e as mortes em consequência da COVID-19 e garantir o direito à vida ${ }^{21}$; (vi) realização de vídeo pelos próprios moradores com o registro de suas demandas e dificuldades vividas na pandemia; (vii) publicação ${ }^{22}$, lives ${ }^{23}$ e entrevistas da coordenação ${ }^{24}$; (viii) elaboração e assessoramento ao projeto piloto do assentamento Fazendinha-Sapês para a regularização fundiária; (ixi) criação em setembro deste ano (2020) do Boletim Mensal "De Olho no NEPHU”, espaço de divulgação das atividades que estamos desenvolvendo e os principais desafios enfrentados na pandemia da Covid-1925.

${ }^{21}$ A pesquisa pode ser acessada no link: < https://bit.ly/35R3LQ5 $>$. Acesso em: 05 ago. 2020.

${ }^{22}$ BIENENSTEIN, G.; BIENENSTEIN, R.; SOUSA, D. M. M. O Coronavírus, a Cidade e a Arquitetura: o caso brasileiro como um (possível) laboratório de horrores. In: BORGES, A.; MARQUES, L. (Orgs.). Coronavírus e as Cidades Brasileiras: reflexões durante a pandemia. Rio de Janeiro: Outras Letras, 2020. p. 96-100.

${ }^{23}$ Pós lançamento do livro acima foram realizadas duas lives que se encontram disponíveis nos sites:

<https://www.youtube.com/watch?v=TLcZdEB25B8>. e < https://www.youtube.com/watch? $\mathrm{v}=\mathrm{O} 3 \mathrm{gMRqTwTFU} \&$ feature $=$ youtu.be\&fbclid $=\mathrm{IwAR} 2 \mathrm{l} 2 \mathrm{cgbbzj} 2 \mathrm{H} 34 \mathrm{fc} 2 \mathrm{hzs} 3 \mathrm{bc} 5 \mathrm{CMRd}-$

PsXIDLFHhEEi-QkEpdrNJzS GbOY $>$.

${ }^{24}$ Entrevista da coordenadora, publicado no site da UFF, no dia 04 de maio de 2020, intitulada "A solidão das superpopulosas favelas no combate à maior crise sanitária do século", conforme o link: <http://www.uff.br/?q=noticias/04-05-2020/solidao-das-superpopulosas-favelas-nocombate-maior-crise-sanitaria-do-seculo $>$. Entrevista recente coordenadora ao Sindicato dos Arquitetos do Rio de Janeiro, disponível em: < $\underline{\text { https://www.youtube.com/watch? } \mathrm{v}=\mathrm{XMDUfG}-}$

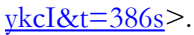

${ }^{25}$ Para maiores informações ver o link: 
As marcas da negligência da extensão universitária nas universidades públicas têm sido agravadas pela (contra)Reforma Educacional, Previdenciária e Trabalhista. Contraditoriamente, a tríade da indissociabilidade e associada ao projeto capitalista,

Tem promovido, sistematicamente, a deteriorização das condições para a produção de conhecimento no campo educacional em particular, as atuais políticas brasileiras para a pós-graduação como a redução de bolsas de estudo, pouco ou nenhum financiamento, definição de prazos aligeirados para a conclusão dos cursos de pós-graduação stricto senso, a proliferação dos mestrados e doutorados profissionalizantes. $\mathrm{O}$ viés da produtividade se impõe e vem ditando uma redução na qualidade das pesquisas, sem contar no pouco ou inexistente incentivo a ações extensionistas. (OLIVEIRA, 2010, online. grifo da autora).

Nesta concepção de universidade, desvinculada dos interesses das classes populares e coadunada à produtividade subordinada aos interesses do capital internacional, consideramos relevantes as experiências de ações extensionistas vinculadas aos movimentos sociais.

Inúmeros fatores vão desfavorecer a realização da extensão universitária e, consequentemente, a concretização do princípio da indissociabilidade anunciado, entre os quais destacamos: a estrutura departamental que favorece o desenvolvimento de ações individuais isoladas; os programas de pós-graduações que vão referir-se, primordialmente, à questão da produção do conhecimento - pesquisa. Os processos de avaliação e planos de carreira docente que desvalorizam as ações extensionistas; a não disponibilização de dotação orçamentária voltada para projetos de extensão universitária, o sucateamento que vem sofrendo a educação superior pública, a desvalorização docente, a precarização do trabalho docente etc. (OLIVEIRA, 2010, online).

Neste sentido, reivindicamos a Educação popular como “[...] uma forma de fazer educação que contribui para a mobilização e organização dos trabalhadores e favorece o despertar para uma consciência crítica, considerando nessa concepção a dimensão da classe e a necessidade de ultrapassar essa ordem societária” (SANTOS, 2017,p.305 ???), concepção esta que se constitui como 
ponto de intersecção com as organizações da classe trabalhadora, e que coaduna com as lutas anticapitalistas e populares ${ }^{26}$.

Com o exposto, acreditamos que as ações extensionistas numa proposta dialogada e participativa não se trata de uma ação isolada, mas de uma ação que integra ensino, pesquisa e extensão, o que pode ser comprovado pelo número de coletivos populares e instituições envolvidas, conforme se observa no programa e seus projetos.

\section{ALGUMAS CONCLUSÕES: EM DEFESA DA TRÍADE ENSINO, PESQUISA E EXTENSÃO}

Contrariando a secundarização da extensão universitária na relação com ensino e pesquisa, a experiência aqui examinada, que pretende ser coerente com os dilemas sociais vinculado a luta das classes populares, é uma produção de conhecimento comprometida com o projeto de nação de horizonte emancipatório. O desafio é negar experiências baseadas em feudos, com pesquisas isoladas, e pensar o compromisso com as classes populares nos dilemas da sociedade brasileira, tendo clareza sobre as razões pelas quais consideramos que a extensão qualifica a universidade.

O princípio da indissociabilidade e as forças contra hegemônicas no interior das universidades brasileiras coloca uma questão fundamental: a construção de um projeto de universidade na direção da formação humana e da democratização do conhecimento, na participação dos coletivos populares na universidade e do reconhecimento do diálogo de saberes.

As reflexões aqui desenvolvidas pretendem dar formato à experiência de trabalho de extensão, como um espaço pedagógico para a aprendizagem dos grupos envolvidos, sejam eles sujeitos da universidade ou da comunidade. Nessa perspectiva, partimos do princípio de que o conhecimento se constrói através da criação compartilhada entre educadores e educandos, seres singulares, pertencentes a diferentes realidades e histórias de vida, valores, sonhos e proje-

\footnotetext{
${ }^{26}$ O conceito de "popular" diz respeito ao conceito de "grupos sociais subalternos" desenvolvido nos Cadernos do cárcere por Gramsci. Para maiores informações ver: GRAMSCI, A. Cadernos do cárcere. v. de 1 a 6. Rio de Janeiro: Civilização Brasileira, 2001.
} 
tos. Com esta metodologia, pretendemos promover, portanto, a ação coletiva e potencializar o espírito crítico e participativo.

Dialogamos com Freire (2001) que afirma que a educação popular é o pensamento no campo da educação que estimula uma formulação mais próxima e coerente com os princípios da participação popular, como um processo político sustentado no diálogo de saberes e da humanização das pessoas. Portanto, considerando esta dimensão da educação popular, a experiência da extensão universitária que o NEPHU vem desenvolvendo, ratifica que o diálogo junto aos sujeitos envolvidos possibilita contribuições para ampliar a leitura sobre a realidade e, assim, promover aos sujeitos a identificação do seu protagonismo em suas ações e de suas histórias individuais e coletivas, além de provocar a construção de estratégias para a incorporação de demandas e necessidades dos coletivos na agenda pública da urbanização e regularização fundiária.

Sendo assim, devem ser valorizadas, qualificadas e adotadas os processos de educação permanente para o controle social e de mobilização em defesa do direito à terra e à cidade, consolidando experiências relevantes para a defesa da democratização das políticas públicas, quais sejam:

1- A compreensão da extensão universitária na direção contra hegemônica que permeia a relação com a comunidade e o fortalecimento dos movimentos sociais da classe trabalhadora. Fazer história requer situar o indivíduo nas lutas mais gerais da classe trabalhadora; requer o fortalecimento das lutas e movimentos mais gerais de defesa dos interesses das classes trabalhadoras; significa afirmar a extensão universitária como central onde a resistência e luta se fazem presentes nas ações extensionistas.

2- A ressignificação da extensão universitária com a publicação da Resolução do Conselho Nacional de Educação ${ }^{27}$ na qual as atividades de extensão devem compor, no mínimo, 10\% (dez por cento) do total da carga horária curricular estudantil dos cursos de graduação, as quais deverão fazer parte da matriz curri-

\footnotetext{
${ }^{27}$ A resolução publicada é no 7, DE 18 DE DEZEMBRO DE 2018 que "Estabelece as Diretrizes para a Extensão na Educação Superior Brasileira e regimenta o disposto na Meta 12 Meta 12.7 da Lei $n^{\circ}$ 13.005/201 que aprova o Plano Nacional de Educação - PNE 2014-2024 e dá outras providências.
} 
cular dos cursos" impõe, na correlação de forças, outro formato de disputa entre os recursos financeiros, envolvimento docente e discente na extensão universitária e o seu legado. Portanto, dialogando com Santos (2017, p. 27), “[...] talvez seja necessário recolocar o debate da extensão como espaço em potencial para o desenvolvimento de ações de Educação Popular”.

3- Reivindicar a negação da laterização da extensão universitária no interior da universidade, com a superação das seguintes dificuldades:

(1) recursos públicos orçamentários insuficientes para a extensão; (2) o rareamento de incentivo docente para ações extensionistas; (3) o parco número de bolsas para docentes e discentes; (4) desvalorização do lugar da extensão para as ações de pós-graduação que se expressa nas plataformas de coletas de dados; (5) ações extensionistas que servem de apêndice das pesquisas (6) e a proliferação de ações, aparentemente, gratuitas, mas que escamoteiam mecanismos de venda de serviços educacionais e de consultorias técnicas. (OLIVEIRA; SANTOS; BIENENSTEIN, 2019, p. 55).

Por fim, com esses eixos, entendemos: (i) a potencialidade no fortalecimento dos espaços de diálogo com o poder público; (ii) o estímulo da participação dos grupos sociais, movimentos sociais e moradores/as nas instâncias de controle social e na redução de desigualdades pelo reordenamento territorial; (ii) a reversão da extensão universitária no interior da universidade na disputa de interesses antagônicos.

\section{REFERÊNCIAS}

ANTUNES, R. Trabalho precário, intermitente, é a antessala do desemprego. Sociólogo analisa o futuro do trabalho no Brasil e a nova massa superexplorada da era dos serviços digitais. Brasil de Fato. Brasil de Fato, São Paulo, 29 abr. 2019. Disponível em: < https://www.brasildefato.com.br/2019/04/29/trabalho-precario-intermitente-e-a-antessala-do-desemprego-diz-ricardo-antunes>. Acesso em: 02 set. 2020. 
Coronavírus [recurso eletrônico]: o trabalho sob fogo cruzado. 1. ed. São Paulo: Boitempo, 2020.

BIENENSTEIN, G.; BIENENSTEIN, R.; SOUSA, D. M. M. O Coronavírus, a Cidade e a Arquitetura: o caso brasileiro como um (possível) laboratório de horrores. In: BORGES, A.; MARQUES, L. (Orgs.). Coronavírus e as Cidades Brasileiras: reflexões durante a pandemia. Rio de Janeiro: Outras Letras, 2020. p. 96-100.

BIENENSTEIN, Regina. Redesenho urbanístico e participação social em processos de regularização fundiária. Tese de Doutorado, PO. SCHERER, Rebeca. São Paulo: USP, 2001.

. Universidade Púbica e o direito à cidade: assessoria a movimentos so-

ciais do Estado do Rio de Janeiro. Programa de Extensão Universitária. Núcleo de Estudos e Projetos Habitacionais e Urbanos (NEPHU). Universidade Federal Fluminense, 2020. Disponível em: < http://nephu.sites.uff.br/programa/ >. Acesso em: 04 set. 2020.

BOGO, Ademar. O papel e os desafios da formação. Mimeo. Bahia, 2000. CHESNAIS, Francois. Capitalismo está diante de uma parede, diz Chesnais. Entrevistas em destaque por Eleonora de Lucena e Rodolfo Lucena. Tutameia. Entreveros e Desenredos. 1 de maio de 2020. Disponível em: $<\underline{\text { https: / tutameia.jor.br/capitalismo-esta-diante-de-uma-parede-diz-ches- }}$ nais/>. Acesso em: 01 set. 20.

FREIRE, P. A importância do ato de ler: em três artigos que se completam. 18. ed. São Paulo: Autores Associados, 1997.

. Pedagogia da autonomia: saberes necessários à prática educativa. 8 . ed. Rio de Janeiro: Paz e Terra, 1998.

Política e Educação. 5. ed. São Paulo: Cortez, 2001.

GOERGEN, P. Dimensões da autonomia universitária no contexto da crise. In: RAYS, O. A. (org). Trabalho pedagógico: realidades e perspectivas. Porto Alegre: Sulina, 1999. 
GOHN, M. da G. Movimentos sociais na contemporaneidade. Revista Brasileira de Educação. Rio de Janeiro: Associação Nacional de Pós-Graduação e Pesquisa em Educação (ANPED), v. 16, n. 47, p. 333-361, maio/ago. 2011. GRAMSCI, A. Obras escolhidas. Rio de Janeiro: Martins Fontes, 1976.

Os intelectuais e a organização da cultura. Rio de Janeiro: Civilização Brasileira, 1978.

. Cadernos do cárcere. v. 1-6. Rio de Janeiro: Civilização Brasileira, 2001.

HOLSTON, James. Rebeliões metropolitanas e planejamento insurgente no século XXI. Revista Brasileira de Estudos Urbanos. Recife, v.18, n. 2042, p.191-204, 2016.

IASI, M. Processo de Formação da Consciência. São Paulo: Editora CPV, 2007.

JESUS, Carolina Maria de. Quarto de despejo. Diário de uma favelada. São Paulo: Livraria Francisco Alves (Editora Paulo de Azevedo Ltda), 1960, 182 p.

LARA, R. Pandemia e capital: as repercussões da Covid-19 na reprodução social. Revista Libertas, Juiz de Fora, v. 20, n. 1, p. 53-69, jan./jun. 2020.

LUCE, M. S. Teoria Marxista da Dependência. Problemas e categorias uma visão histórica. São Paulo: Expressão Popular, 2018.

MARINI, R. M. Dialética da dependência. Trad. Marcelo Dias Carcanholo. In: STÉDILE, J. P.; TRASPADINI, R. (orgs.). Ruy Mauro Marini: vida e obra. São Paulo: Expressão Popular, 2005.

MARX, K. O capital: crítica da economia política. Livro I: o processo de produção do capital. São Paulo: Boitempo, 2013.

MÉZÁROS, I. A educação para além do capital. São Paulo: Boi tempo, 2005.

OLIVEIRA, A. C.; SANTOS, F. H. C. dos; BIENENSTEIN, R. Movimentos sociais urbanos, extensão universitária e Serviço Social: a experiência interdisci- 
plinar da assessoria técnica. Temporalis, Brasília, ano 19, n. 38, p. 52-69, jul./ dez. 2019.

OLIVEIRA, C. B. de. Ensino, pesquisa, extensão: indissociáveis ou não? Revista Digital, Buenos Aires, año 14, n. 140, ene. 2010, on line. Disponível em: < https://www.efdeportes.com/efd140/ensino-pesquisa-extensao.htm >. Acesso em: 04 set. 2020.

OLIVEIRA, F. L. de; SÁNCHEZ, Fe.; VAINER, C. Planejamento Conflitual na Cidade Olímpica: a experiência da Vila Autódromo. Rio de Janeiro, 2020, p. 1-22 . Disponível em: < https://contrapoder.net/wp-content/uploads/2020/09/Planejamento-Conflitual-na-Cidade-Olimpica-a-experienciada-Vila-Autodromo-Rio-de-Janeiro.pdf >. Acesso em: 25 set. 2020.

OSORIO, J. Dependência e superexploração. In: MARTINS, C. E.; SOTELO VALENCIA, A. (orgs.). A América Latina e os desafios da globalização: ensaios dedicados a Ruy Mauro Marini. São Paulo: Boitempo Editorial, 2009, p. 167-188.

SANTOS, F. Considerações sobre a educação popular e o Serviço Social: um diálogo com os pressupostos freirianos. Movimento-Revista de Educação, Niterói, ano 4, n. 7, p. 303-325, jul./dez. 2017.

SILVA, T. T. Teoria Cultural e Educação. Um Vocabulário Crítico. Belo Horizonte: Autêntica, 2000.

THIOLLENT, M. Metodologias participativa e sua aplicação em projetos de extensão universitária. In: THIOLLENT, M.; ARAÚJO FILHO, T. de; SOARES, R. L. S. (orgs.) Metodologias e experiências em projetos de extensão. Niterói: EDUFF, 2000. p. 19-28.

VALE, A. M. do. Educação popular na Escola Pública. São Paulo: Cortez, 1992. 